\title{
A Method of Container Terminal Resources Scheduling Simulation Research
}

\author{
Li Mingqi, Zhang Peng*, Du Yuyue \\ College of Information Science and Engineering, Shandong University of Science and Technology \\ Qing Dao, China \\ *bigbigroc@163.com
}

Keywords:terminal emulation; resource allocation; scheduling; optimal solution

Abstract: In order to study the impact of container terminals in different resource allocation and scheduling device efficiency of terminal operations, using FlexTerm software to establish a terminal simulation model for the simulation of transportation operations research, through the simulation experiment under different configuration scheme for equipment utilization comparative analysis of various resources, the results will provide a reference for the study of terminal resources utilization.

\section{Introduction}

The container terminal is connected with the ocean shipping and land transportation, is the sea land multimodal transportation hub. Because of the the container terminal has the characteristics of large investment, long construction period, large mechanical facilities and large amount of operation and so on.How to improve the operation efficiency of the container terminal, reduce the corresponding operating costs, has become the focus of the dock companies. And because of the complexity of the container terminal operation system, researchers will usually these terminal operation system is divided into several sub problems to solve, such as berth planning, allocation of crane, container truck allocation, allocation of gantry crane, yard resource allocation, and so on.

Many experts and scholars have carried out a series of research on the problem of container terminal resource allocation. W.C.Ng [1] etc. research is a single gantry crane scheduling problem, considered each container ready time. In this paper, we set up to minimize all the waiting time and target IP model, using a branch and bound algorithm to solve the model. In the research field of multi crane scheduling, in accordance with its consideration of the disturbance between two kinds of division of gantry crane. D.H.Lee [2] consider two gantry cranes scheduling, established to minimize completion time for the mathematical model of the target, and simulated annealing algorithm to solve the model. W.C. $\mathrm{Ng}[3]$ is the study of crane scheduling problem in a two-way track multiple crane work. In this paper, we consider several gantry cranes exist interference. To solve this problem, set up a to minimize the overall finish time of the integer programming (IP) model, and propose a heuristic dynamic programming method to solve the model. W.Li [4] research the interference of gantry crane scheduling problem, compare with W.C.Ng[3], W.Li [4] also considers a gantry crane safety distance. Literature [5] studied is crane and truck dispatching, based on production line process, namely multi trucks service in the same crane, in the condition of considering the operation of terminal container, The MIP model is established to minimize the total time of all jobs, using genetic algorithm and based on Johnson's rule improved heuristic algorithm to solve the model. Study on three kinds of handling equipment such as L.Chen [6], namely crane, gantry crane and truck dispatching field, the load and discharge of port container is regarded as a mixed flow shop scheduling problem, and the cooperative scheduling scheme for the three equipments is presented. H.Y.K.Lau[7]etc. Also research three kinds of load and discharge equipment integrated scheduling, the target is establish a minimize AGV walking time, QC leisure time and AYC total travel time for MIP model. Jinxin Cao [8] was studied for the first time on the truck and crane scheduling, a MIP model is set up to minimize the completion 
time of the last job, use two kinds of methods -- general Benders decomposition and combined Benders decomposition to solve the model.

In summary, the existing literatures in the single crane, the truck dispatching is thorough study but the research on the coordination of a variety of equipment is not deep enough. In this paper, we use the method of the job line and the job surface respectively the optimal allocation ratio of many kinds of equipments are obtained by simulation experiment.

\section{Resource Allocation And Trucks Scheduling Method}

\section{Container terminal operation process}

The traditional container terminal can be divided into three basic regions: Berth for parking container ships, Access systems control trucks in and out and Yard used for stacking containers. The discharge process of the container terminal is generally as follows: first, the ship enters the berth, the crane will lift import containers from the ship to truck, and then transport the container to the yard by truck, the container is discharged to the designated position by the gantry crane, and the truck back. While in the course of load operation, The gantry crane will lift export container from the yard to truck, And then transport the container to the shore by truck, use the crane load the export containers to ship, and the truck back. The terminal resource allocation problem refers to allocate a certain number of the truck, crane and gantry crane, to achieve the smooth operation of container terminals, so as to improve the operation efficiency of the terminal.

\section{model configuration}

The experimental model is based on the following points:

(1) Analysis of the unloading operation only;

(2) The amount of the work during the planned period and the job occurrence are always known.;

(3) The crane can ensure the work during the operation, that is, the accident will not happen to interrupt the operation ;

(4) The crane and gantry crane can only take one container at a time;

(5)Each yard is equipped with a gantry crane.

For ease of modeling, the following parameters are introduced:

$\mathrm{c}_{\mathrm{i}}$ : the time use crane to complete the task of $\mathrm{i}(1 \leq \mathrm{i} \leq \mathrm{n})$;

$\mathrm{g}_{\mathrm{i}}$ : the time use Gantrycrane to complete the task of $\mathrm{i}(1 \leq \mathrm{i} \leq \mathrm{n})$;

$\mathrm{v}_{\mathrm{i}}$ : the time use truck to complete the task of $\mathrm{i}(1 \leq \mathrm{i} \leq \mathrm{n})$;

$t_{i}$ : the period time of Complete the task $\mathrm{i}(1 \leq \mathrm{i} \leq \mathrm{n})$,

$$
\mathrm{t}_{\mathrm{i}}=\mathrm{c}_{\mathrm{i}}+\mathrm{g}_{\mathrm{i}}+\mathrm{v}_{\mathrm{i}} \text {; }
$$

Complete the whole operation, to satisfied the

$$
T=\sum_{i=1}^{n} t_{i}
$$

\section{Work line and work surface method}

Work line is a simple scheduling method, the method for each gantry crane specified fixed number of trucks to complete the operation. These trucks only service for single crane, and not involved in the other work. The advantage is that the scheduling method is simple, and the disadvantage is that it can cause waste of resources.

The work surface can be regarded as an optimization of the work line method, which will concentrate all the truck in a pool, when load and discharge operations. the truck according to the scheduling algorithm can be all operation scheduling, work in a more flexible manner, resource utilization rate is also higher, but the requirements of scheduling algorithm is also higher. Specific method as shown in algorithm 1.

Input: ship enter the terminal, Discharge operation;Output: Discharge operation, ship departure 


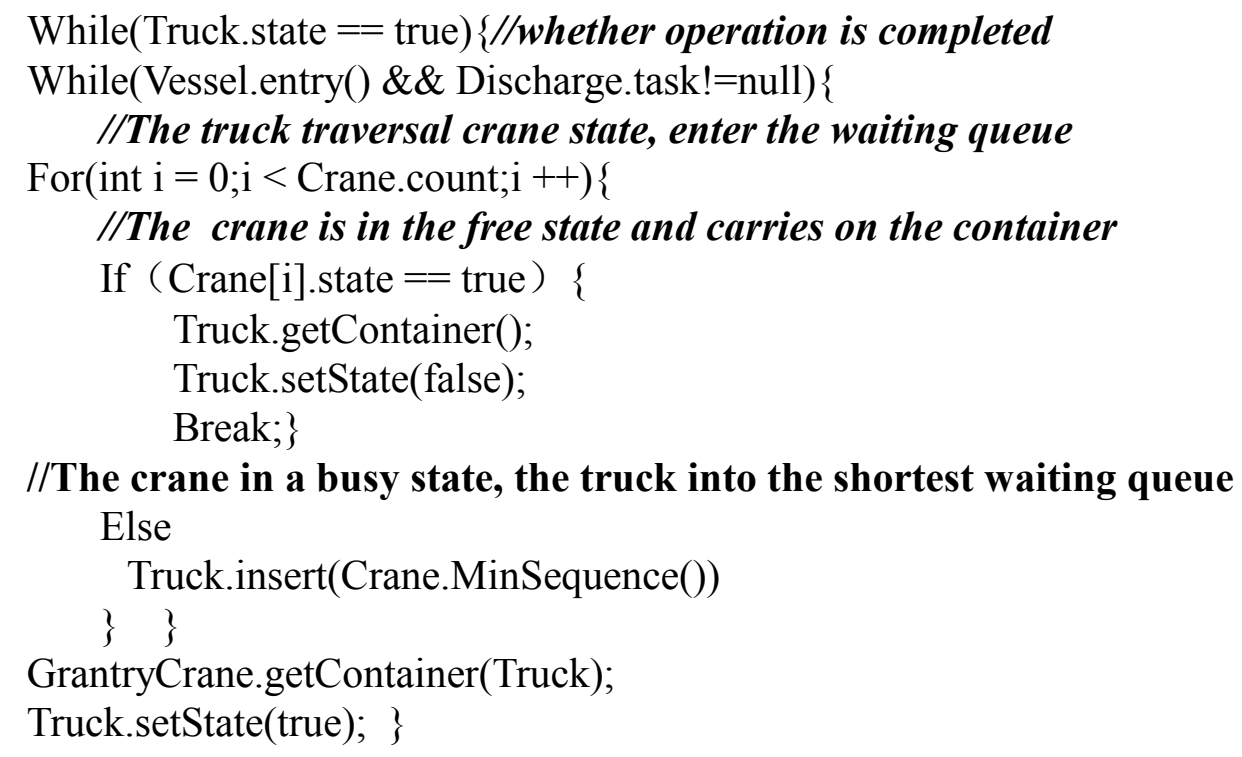

\section{Modeling And Simulation}

Taking FlexTerm as experiment platform, a 4000TEU ship is set up at a pier of a coastline of 800 meters, simulation of its discharge operations. In this model, the container type is 40FT, after the ship arrival terminal, you need to unload 200TEU, that is, unload 100 containers to the yard. The storage strategy of the yard is carried on the stack operation according to the sequence of the bay. The parameters of the whole simulation system are set up before the start of the simulation, and the detailed parameters list is shown in Table 1, and the other parameters are the default values of the system.

Table 1. Parameter list

\begin{tabular}{|l|l|}
\hline \multicolumn{1}{|c|}{ Item } & parameter list \\
\hline Ship & \\
Entry time(s) & 800 \\
Departure time(s) & 800 \\
\hline Crane & \\
Ready time(s) & 10 \\
Load cycle(s) & triangular $(60,180,90)$ \\
\hline Gantry Crane & \\
Discharge cycle(s) & triangular $(30,120,60)$ \\
\hline Truck & triangular $(120,300,180)$ \\
Load cycle $(s)$ & triangular $(120,300,180)$ \\
Discharge cycle $(s)$ & 20 \\
Speed $(\mathrm{km} / \mathrm{h})$ & \\
\hline
\end{tabular}

Through multiple simulations, the time required for each resource equipment operation in a task cycle is determined, and the results are as Table 2.

We will take the data of Table 2. as the basis for the assumption, three simulation experiments are carried out, and the optimization of resource equipment is realized gradually. The first experiment's purpose is through configuration trucks number to improve the utilization rate of crane .Experiment two is on the basis of experiment one, the operation mode based on the work line to get optimal bridge crane and crane, to realize the optimization of resources crane. Experiment three will be based on the experimental two using the work surface operating on the simulation model for further optimization. 
Table 2.Individual job periodic table

\begin{tabular}{|l|l|l|l|l|l|}
\hline time & $\begin{array}{l}\text { No-load } \\
\text { running } \\
\text { time(s) }\end{array}$ & $\begin{array}{l}\text { Full load } \\
\text { running } \\
\text { time(s) }\end{array}$ & $\begin{array}{l}\text { Idle } \\
\text { waiting } \\
\text { time(s) }\end{array}$ & $\begin{array}{l}\text { Utilization } \\
(\%)\end{array}$ & $\begin{array}{l}\text { Single } \\
\text { operation } \\
\text { time(s) }\end{array}$ \\
\hline item & 96.2 & 86 & 110.6 & $62.2 \%$ & 292.8 \\
\hline
\end{tabular}

\section{The first simulation experiment}

The research object of this simulation experiment is bridge crane. By allocating different number of trucks to a bridge crane to calculate the utilization of the bridge crane, the following assumptions are based on the data in Table 1: In one work cycle, the bridge crane can complete the loading and unloading times $\mathrm{Nc}=\mathrm{t} / \mathrm{c}$. It is seen by the data in the table 1 , in a work cycle bridge crane operation time is about 153.6, and the entire operation time is 292.8. So the bridge crane can operate on containers twice at a work cycle. It may be assumed that the best allocation ratio bridge crane and trucks is $1: 2$. To validate the assumption different number of cranes and the trucks will be tested and the results are shown in Table 3, Fig. 1. and Fig. 2.

From fig.1, fig. 2 and table 3, it is obvious to see that the operation time is cut half down when the number ratio of bridge crane and truck change from 1:1 to1:2. At the same time bridge cranes utilization change from $57.8 \%$ to $94 \%$ and the utilization rate of gantry crane change from $35.8 \%$ to $59.2 \%$, while the utilization rate of trucks from $97.3 \%$ to $81.4 \%$. When the number of container trucks increase, the utilization rate of the bridge crane does not improve. It shows that the bridge crane has reached saturation. When there is one gantry crane, the optimal ratio of bridge cranes and trucks is $1: 2$, the e utilization of the resource is maximized.

Table 3. The Simulation results of different ratio of bridge crane and truck

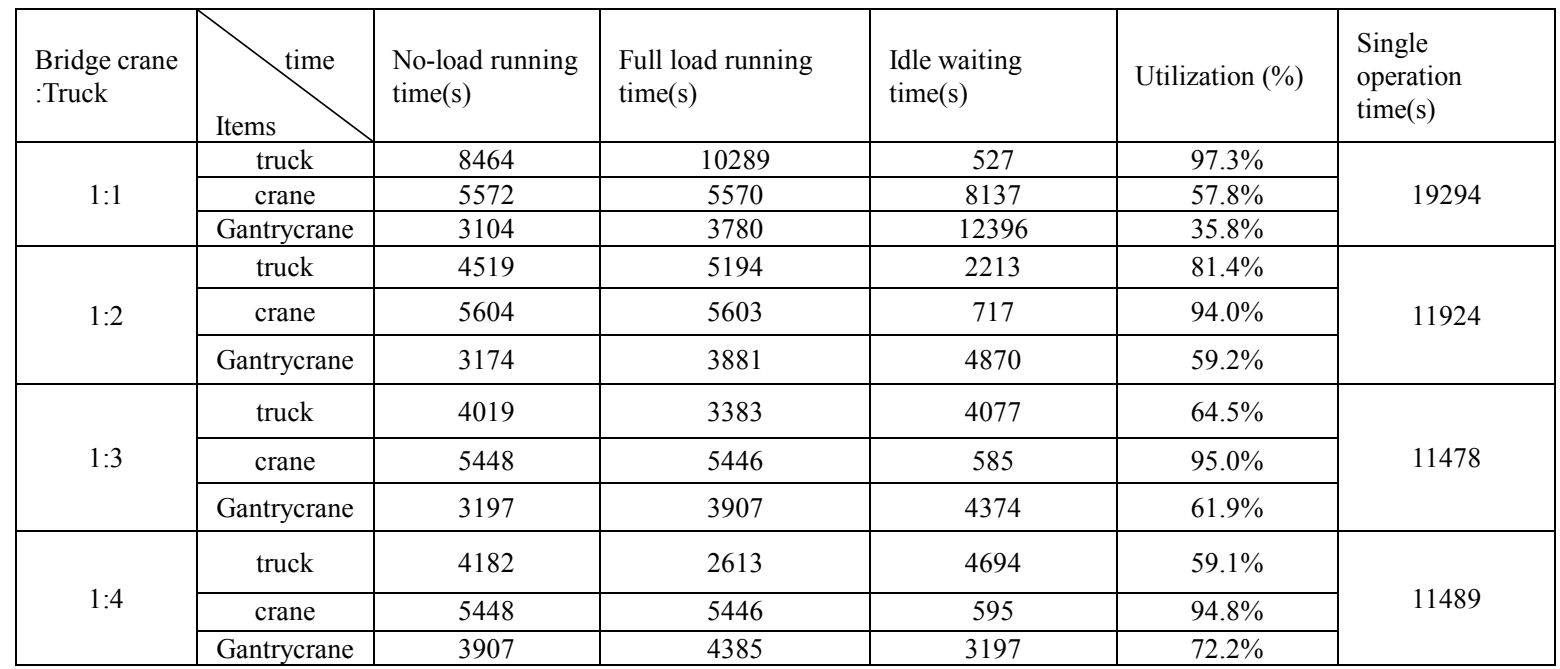

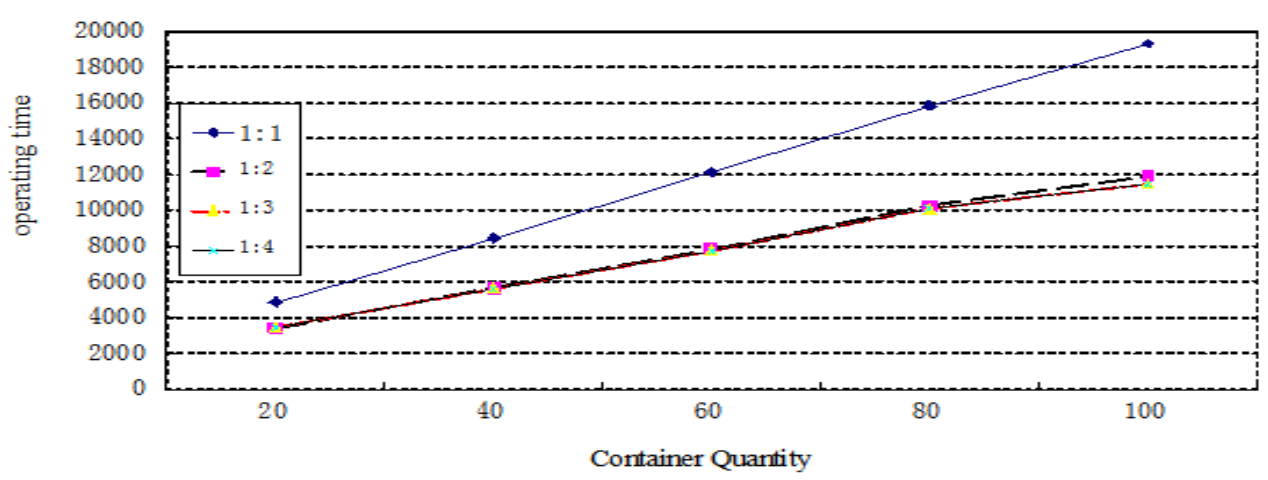

Fagure 1. The operating time of different ratio of trucks and bridge crane 


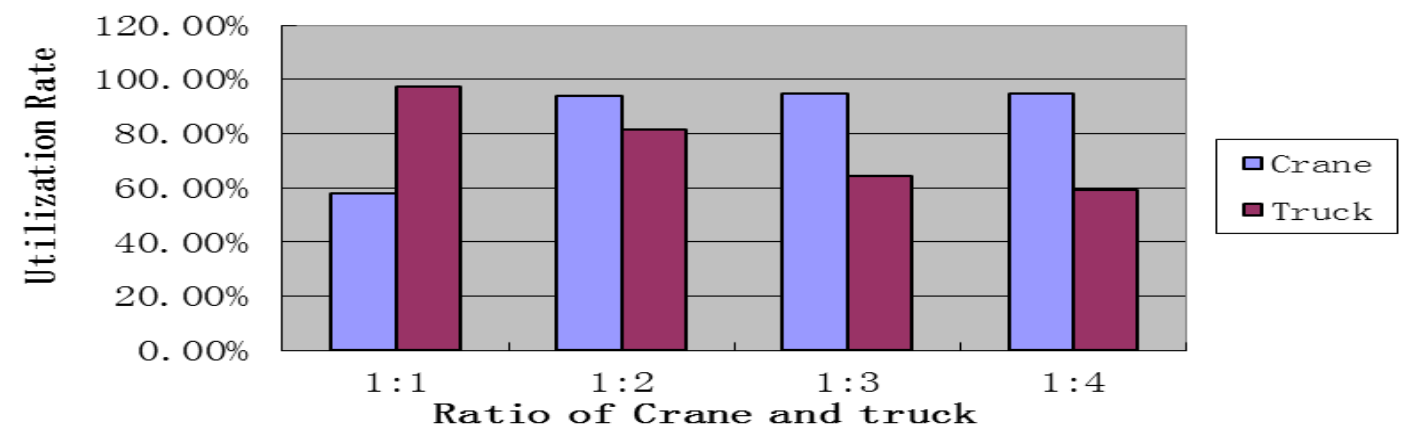

Fagure 2. The Utilization different ratio of cranes and trucks

\section{The second simulation experiment}

The second Simulation experiment is to increase utilization of gantry cranes based on operating line. From the first experiment, when the bridge crane has reached saturation, we can increase the number of bridge crane rather than trucks. According to the first experiment in one work cycle, a maximum amount of $\mathrm{Ng}=\mathrm{t} / \mathrm{g} \approx 4$. This means that a gantry crane can finish 4 times operations in one operation cycle. Based on the operating line, the second experiment gives the utilization of different ratio of gantry cranes and bridge cranes.

Analysis table 4. Figure3. And figure 4, The utilization is highest when the ratio of bridge cranes, gantry cranes and trucks is $1: 2: 4$.

Table 4. The Simulation results of different ratio of cranes, gantry cranes and trucks

\begin{tabular}{|c|c|c|c|c|c|c|}
\hline $\begin{array}{l}\text { gantry crane : crane: } \\
\text { truck }\end{array}$ & Items & $\begin{array}{l}\text { No-loa } \\
\text { d running } \\
\text { time(s) }\end{array}$ & $\begin{array}{l}\text { Full load } \\
\text { running } \\
\text { time(s) }\end{array}$ & $\begin{array}{l}\text { Idle } \\
\text { waiting } \\
\text { time(s) }\end{array}$ & $\begin{array}{l}\text { Utilization } \\
(\%)\end{array}$ & $\begin{array}{l}\text { Single } \\
\text { operation } \\
\text { time(s) }\end{array}$ \\
\hline \multirow{3}{*}{$1: 1: 2$} & truck & 4519 & 5194 & 2213 & $81.4 \%$ & \multirow{3}{*}{11924} \\
\hline & bridge crane & 5604 & 5603 & 717 & $94.0 \%$ & \\
\hline & Gantry crane & 3174 & 3881 & 4870 & $59.2 \%$ & \\
\hline \multirow{3}{*}{$1: 2: 4$} & truck & 3293 & 3860 & 257 & $96.4 \%$ & \multirow{3}{*}{7410} \\
\hline & bridge crane & 2810 & 2780 & 1820 & $74.5 \%$ & \\
\hline & Gantry crane & 3239 & 3957 & 214 & $97.1 \%$ & \\
\hline \multirow{3}{*}{$1: 3: 6$} & truck & 3250 & 3305 & 679 & $90.6 \%$ & \multirow{3}{*}{7234} \\
\hline & bridge crane & 1943 & 1925 & 3366 & $53.5 \%$ & \\
\hline & Gantry crane & 3164 & 3868 & 202 & $97.2 \%$ & \\
\hline \multirow{3}{*}{$1: 4: 8$} & truck & 3246 & 3138 & 679 & $90.1 \%$ & \multirow{3}{*}{7063} \\
\hline & bridge crane & 1378 & 1360 & 4325 & $38.8 \%$ & \\
\hline & Gantry crane & 3084 & 3769 & 210 & $97.0 \%$ & \\
\hline
\end{tabular}

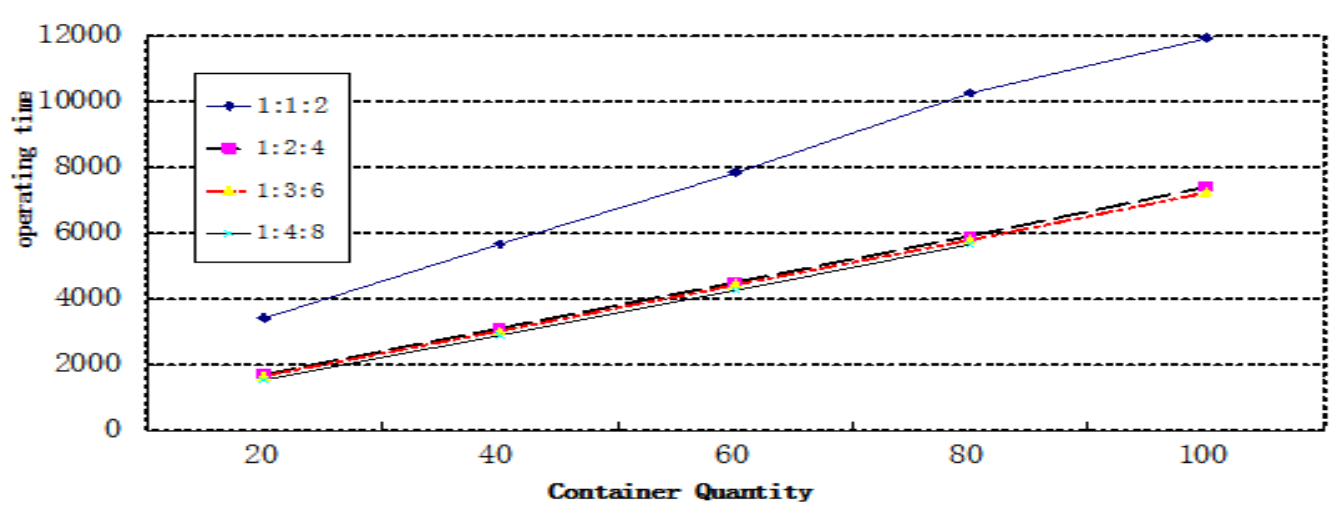

Figure3. The operating time of different ratio of cranes, gantry cranes and trucks 


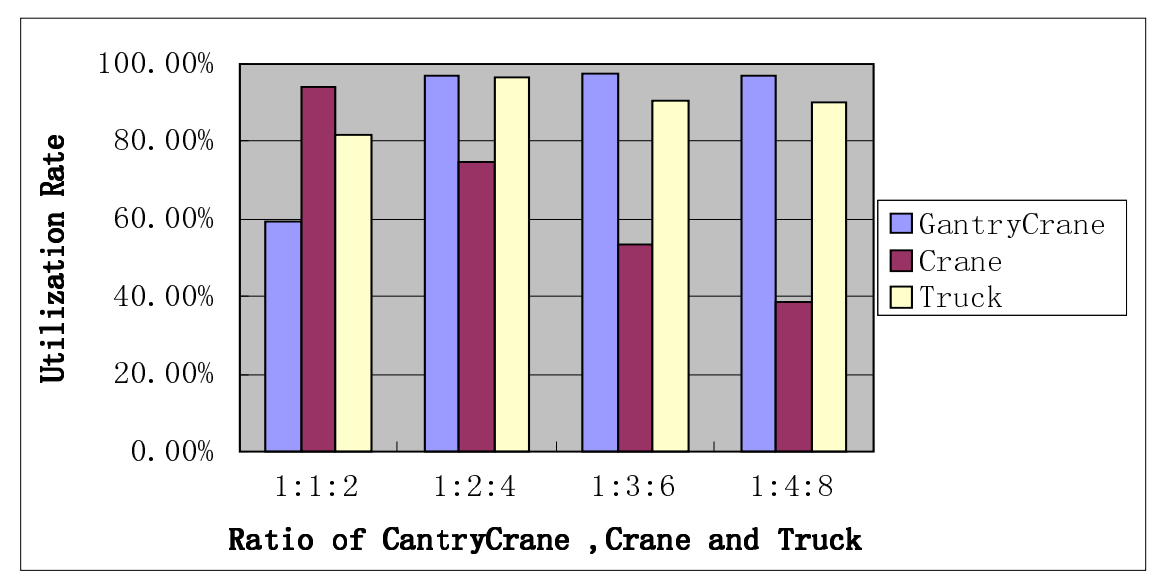

Figure 4 The Utilization different ratio of cranes, gantry cranes and trucks

\section{The third simulation experiment}

The third experiment is to optimize model of the second experiment based on the work surface. In this experiment the ratio of bridge cranes and gantry cranes is fixed 1:2, the trucks numbers are flexible, the simulation results are as follows.

Analysis the experimental data, the ratio of gantry crane and bridge crane is 1:2 and the dispatch method of trucks is based on the operating surface. We find that when the ratio of gantry crane, bridge crane and truck is $1: 2: 3$, the resource utilization is the highest.

Table 5. The Simulation results based on operating line

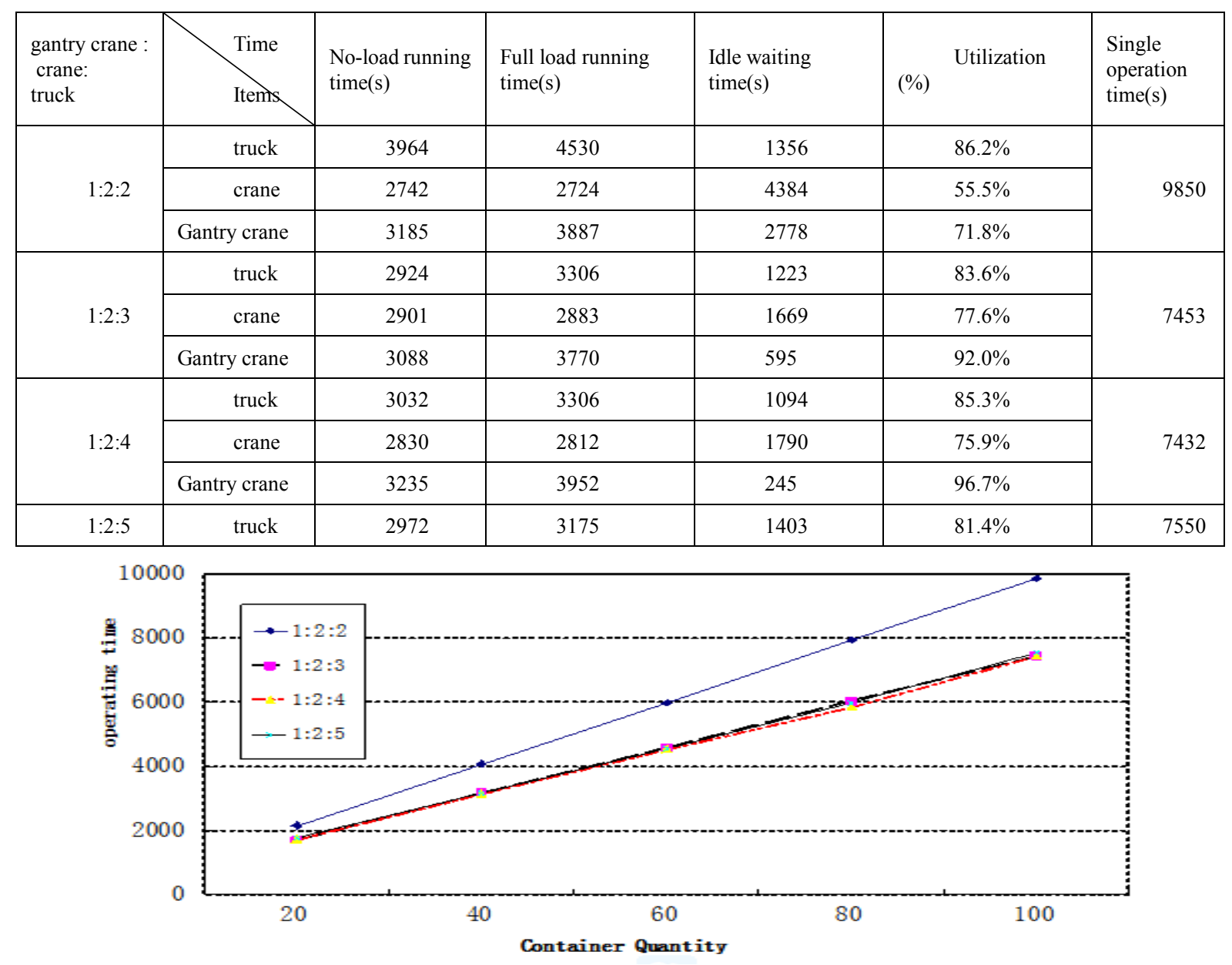

Figure 5 The operating time of operating line 


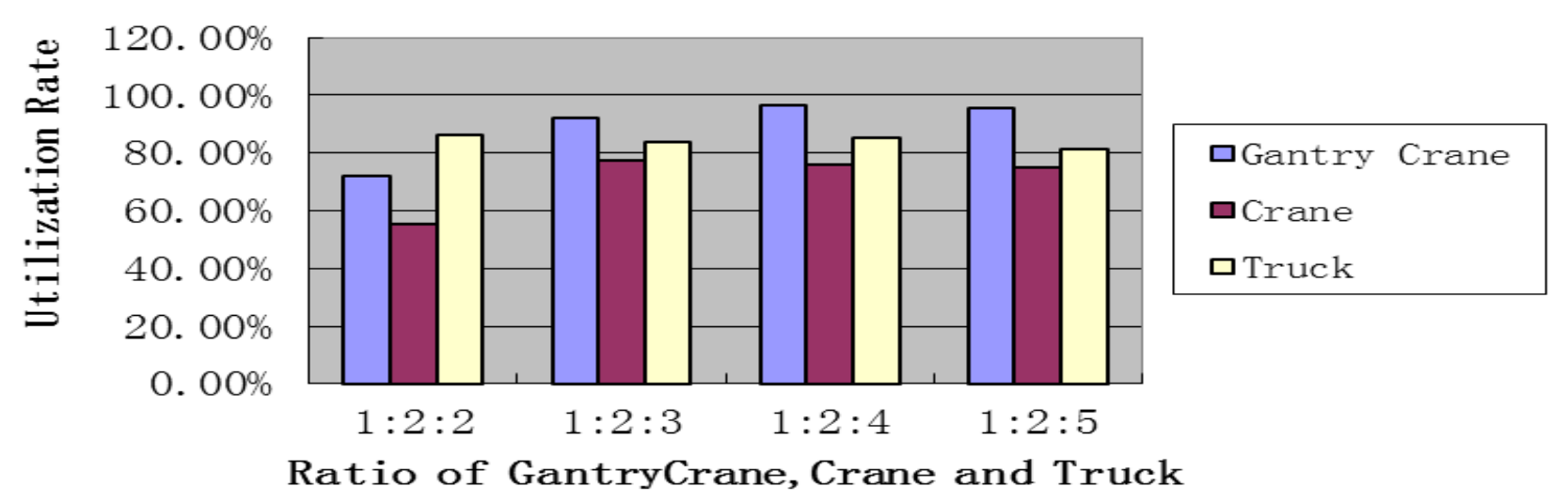

Figure 6 The Utilization e of operating line

\section{Conclusions}

The simulation results show that when a specific resource device saturation add other devices will only make a little increase utilization of the equipment but the utilization of other devices will be greatly reduced, the overall working time will not shorten. Optimized scheduling algorithm can use fewer resources to obtain better results; therefore optimization of resources for container terminal equipment must be solved as a whole, particular resource utilization equipment problem will not shorten the overall operating time.

\section{Acknowledgment}

This research was financially supported by the National Natural Science Foundation of China under grants 61170078 and 61472228; Basic Research Program of Qingdao City of China under grants No. 13-1-4-116-jch.

\section{References}

[1] Ng W C, Mak K L.Yard crane scheduling in port container terminals[J].Applied Mathematical Modelling, 2005, 29(3): 263-276.

[2]Lee D H, Cao Z, Meng Q.Scheduling of two-transtainer systems for loading outbound containers in port container terminals with simulated annealing algorithm[J].International Journal of Production Economics, 2007, 107(1): 115-124.

[3]Ng W C.Crane scheduling in container yards with intercrane interference[J].European Journal of Operational Research, 2005, 164(1): 64-78.

[4]Li W, Wu Y, Petering ME H, et al.Discrete time model and algorithms for container yard crane scheduling[J].European Journal of Operational Research，2009， 198(1): 165-172.

[5]Cao J X, Shi Q, Lee D H.Integrated quay crane and yard truck schedule problem in container terminals[J].Tsinghua Science and Technology, 2010, 15 (4): 467-474.

[6]Chen L, Bostel N, Dejax P, et al.A tabu search algorithm for the integrated scheduling problem of container handling systems in a maritime terminal[J].European Journal of Operational Research, 2007, 181(1): 40-58.

[7]Lau H Y K, Zhao Y.Integrated scheduling of handling equipment at automated container terminals[J].International Journal of Production Economics， 2008， 112(2): 665-682.

[8]Cao J X, Lee D H, Chen J H, et al.The integrated yard truck and yard crane scheduling problem: benders decomposition-based methods[J].Transportation Research Part E: Logistics and Transportation Review, 2010, 46(3): $344-353$. 